\title{
Tips for Integrating Land and Wildlife Management: Quail and Timber ${ }^{1}$
}

\author{
William M. Giuliano and Lauren Watine ${ }^{2}$
}

In Florida, changes in forest management practices during the past $50+$ years have led to declines in quail habitat and populations. Important changes involve the use of fire and conversion of native forests to commercial pine plantations. A lack of fire and other disturbance has often led to closedcanopy forests with dense undergrowth that lack important quail habitat components.

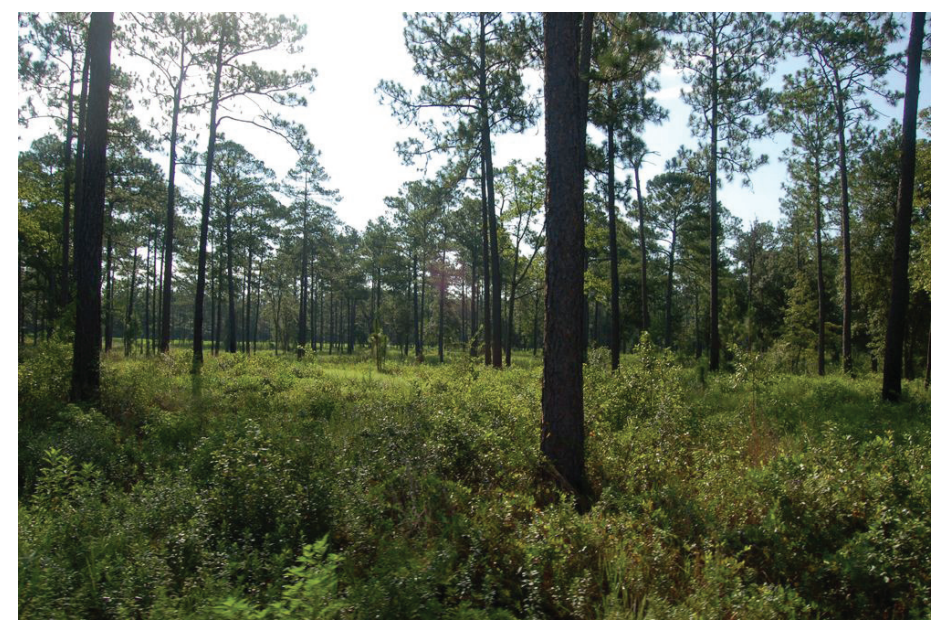

Figure 1. Quail prefer a highly interspersed, "crazy quilt" habitat. Credit: William Giuliano

Bobwhites are a disturbance-dependent species. The diverse, highly interspersed habitat they require, often called the "crazy quilt," cannot persist without habitat changes and upheavals. The ideal quail quilt contains small patches of nesting cover (bunchgrasses such as bluestems), foraging and brood-rearing habitat (weeds such as ragweed and partridge pea), and escape cover (shrubs such as saw palmetto and wax myrtle) mixed among each other in roughly equal amounts. While some tree species produce seeds bobwhites eat, and thick, young stands of some species provide cover, trees are generally not important quail habitat components. In forests, quail prefer longleaf pine over other pines because its seeds are a preferred food source and because it can be burned at an early age. In hardwood forests, mast-producing species such as oaks should be promoted because they provide preferred foods (mast includes nuts and fruits). However, although hardwood forests provide food sources for bobwhites, they also tend to harbor more predators of bobwhites and thus may be less desirable than pine-dominated areas.

The primary problem with closed-canopy forest of any age or species composition, though, is that the amount of light that reaches the forest floor is reduced, preventing the growth of the herbaceous plants and sometimes shrubs that provide essential food and cover for quail. While high bobwhite populations can occur in forested areas, this often requires intensive management. Ideally, mature forest stands will have basal areas of less than 30 to 40 square feet per acre, with use by birds decreasing as basal area increases, and ending with basal areas of more than 70 square feet per acre (the basal area of a stand is the sum of the cross-sectional areas, measured 4.5 feet above the ground, of all trees in the stand). Forests should be open and savanna-like (less than 30\% canopy closure)

1. This document is WEC331, one of a series of the Department of Wildlife Ecology and Conservation, Florida Cooperative Extension Service, Institute of Food and Agricultural Sciences, University of Florida. Original publication date January 2013. Visit the EDIS website at http://edis.ifas.ufl.edu.

2. William M. Giuliano, professor; and Lauren Watine, student; Department of Wildlife Ecology and Conservation, University of Florida, Gainesville, FL 32611. 
with an abundance of interspersed, annual and perennial herbaceous vegetation and some shrubs. Any land management practice that promotes these conditions will benefit quail. Prescribed fire is often the least expensive and most effective forest management practice. Your choice of management practice-fire or herbicides, roller chopping or thinning-matters less than your strategy. In order to promote and maintain crazy quilt habitat on your land, you should vary the intensity of disturbances you create, and target different areas in different seasons. Mix up your management efforts spatially, seasonally, and in intensity in order to create the greatest diversity of habitats. Below are specific quail habitat improvement tips that focus on diversifying the plant species and structural composition and increasing early successional communities dominated by herbaceous plants.

\section{Tips}

- Use multiple timber harvesting methods to diversify forest structure (e.g., clearcuts and selective cuts).

- Open closed-canopy forest through timber harvest and thinning to let sunlight reach the forest floor; strive for a savanna-like system.

- Reduce the amount of pine plantation.

- Within pine stands, promote longleaf over other pine species.

- Disturb the soil, ground cover, and understory using fire, roller chopping, and disking to promote early successional plant communities.

- Create forest openings in large expanses of dense, continuous forest (openings should be 1 - 5 acres each and make up more than $25 \%$ of the area).

- Encourage multiple hardwood species to provide a more diverse and consistent mast crop.

- Cut and remove trees selectively to promote beneficial tree and shrub species, especially hard and soft mast producers.

- Delay canopy closure by using wide spacing when artificially regenerating stands through seedlings (aim for 12-foot by 12 -foot spacing or 300 trees per acre).

- Manage food plots containing primarily forbs (especially legumes) with some grasses during both cool and warm seasons (food plots should be 1 - 3 acres each and should make up more than $3 \%$ of the land).

- Maintain odd areas such as ditches, roadsides, corners of fields, etc., that include a diversity of plant species and structures.

Consider these recommendations in the context of the overall forest. For example, when locating a food plot, consider putting it near a mature pine plantation, which has little food or cover value for quail, rather than near a forest opening. An extensive discussion and descriptions of the tips provided here can be found in: Bobwhite Quail in Florida: Ecology and Management by W. M. Giuliano, J. F. Selph, and B. J. Schad, which is available through the UF/ IFAS Extension Bookstore (http://ifasbooks.ifas.ufl.edu).

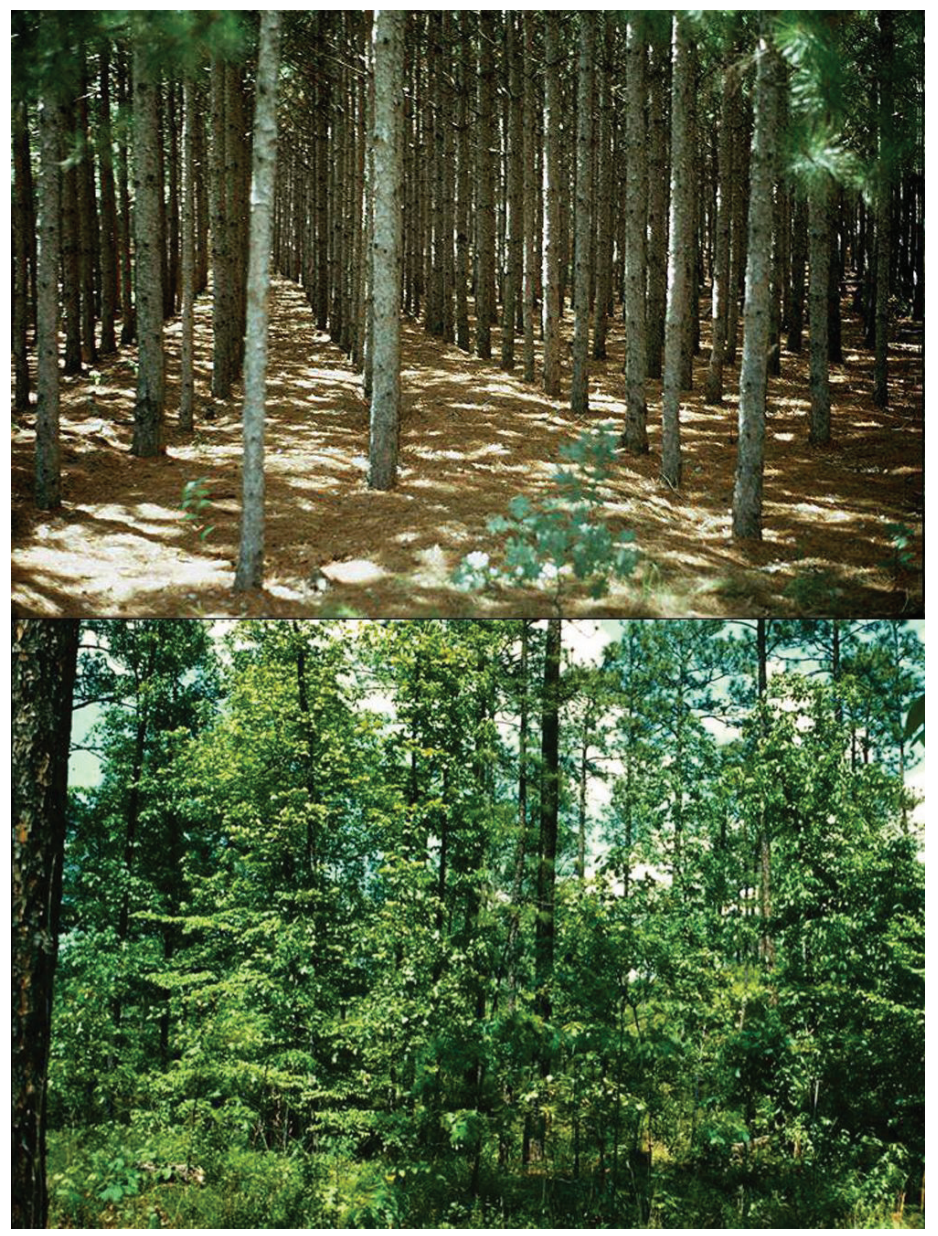

Figure 2. Open closed canopy overstory, understory, and shrub layers and avoid pine plantations to improve quail habitat. Credit: William Giuliano 